\title{
A Three-Level Inverter Based Static Compensator (STATCOM)
}

\author{
Aniagboso John Onah
}

\begin{abstract}
In an electric utility network, the occurrence of voltage depression on transmission and distribution lines is due to the flow of reactive power. It is desirable to regulate the voltage within a narrow range of its nominal value $( \pm 5 \%$ range around their nominal values). Thus, reactive power control is necessary so as to control dynamic voltage swings under various system conditions and thereby improve the power system transmission and distribution performance. A fast acting Static Compensator (STATCOM) is required to produce or absorb reactive power so as to provide the necessary reactive power balance in transmission and distribution system. Modern reactive power compensation employs voltage source inverter (VSI). In this paper, a static compensator based on three-phase, three-level voltage source inverter (VSI) was investigated. The paper is intended to show how this STATCOM can be used to improve the ac system power factor and voltage regulation, and hence improve the performance of the transmission and distribution lines. Application of this STATCOM to a transmission system achieved unity power factor, thereby reducing the active power loss by $38.7 \%$ and consequently decreasing power costs, as well as increasing transmission system capacity. The presence of the STATCOM also reduced the reactive power flowing on the line from $\mathbf{2 . 7 9}$ MVAr to $1745 \mathrm{VAr}$ - resulting in optimum voltage regulation at the load bus. The reactive elements ( $L$ and $C$ ) are small in size.
\end{abstract}

Index Terms-Voltage Regulation; Power Factor; VAR Compensation; Inverter; Total Harmonic Distortion.

\section{INTRODUCTION}

Modern power systems are designed to operate efficiently to supply power on demand to various load centers with high reliability. The generating stations are often located at distant locations for economic, environmental, and safety reasons [1]. Modern industrial processes are based on large amount of electronic devices such as programmable logic controllers (PLCs) and adjustable speed drives. Consequently, industrial loads become less tolerant of power-supply disturbances such as voltage dips, voltage swells, voltage flicker, and harmonics [2]. Voltage dips are considered the most common and severe disturbances to industrial equipment [3]. Voltage dips can be caused by the starting of big loads, but are more often caused by network faults [4]. The flexible AC transmission system (FACTS) is an alternating current transmission system incorporating power electronic-based and other static controllers to enhance controllability and power system operation flexibility which improves the system stability, and achieves better utilization of existing power system [1]. A static compensator (STATCOM) is a member of the flexible alternating current transmission system (FACTS) devices. It is a power-electronics-based regulating device which is composed of a voltage source inverter (VSI) and is shunt connected to alternating current electricity transmission and distribution networks (the grid) to protect sensitive loads against voltage dips [5]. The voltage source is created from a DC capacitor and the STATCOM can exchange reactive power with the network. The function of the STATCOM is to maintain the voltage of the bus connected at a constant value [6]. It can also supply some active power to the network if a DC source of power is connected across the capacitor. A STATCOM is usually installed in the electric networks with poor power factor or poor voltage regulation to mitigate these problems. In addition, it is used to improve the voltage stability of a network. It can simultaneously fulfill different objectives like maintaining a sinusoidal voltage (harmonic free) at the load bus, source current harmonics elimination, load balance, and power factor correction [7], [8]. Three-level inverters offer numerous advantages over two-level inverters, such as improved output voltage quality, higher voltage operating capability, and reduced $d v / d t$ stress. It enables the construction of a high-power converter without the problem of switching series-connected semiconductor devices [9]. Due to these features, three-level inverters are increasingly used in medium/high-voltage, high-power applications such as electric traction system, flexible ac transmission, and static var compensators [10].

\section{PRINCIPLE OF OPERATION}

Fig. 1 shows the circuit diagram of a STATCOM based on three-phase, three-level neutral-point clamped (NPC) voltage source inverter. Its major component is an inverter consisting of 12 switching devices and 16 diodes connected to the ac mains through a transformer, and the leakage reactance of the transformer is represented by $\mathrm{X}_{\mathrm{L}}$ [11], [12]. 


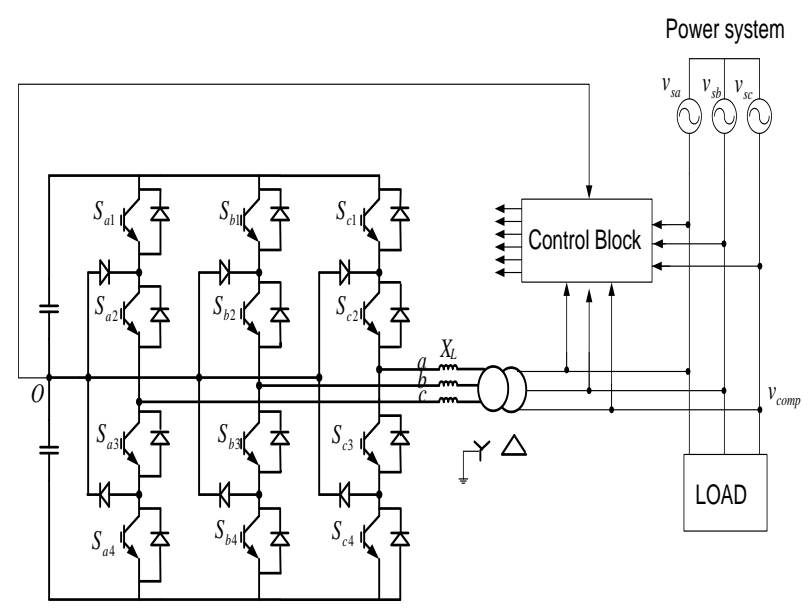

Fig. 1. The power circuit of the ASVC, using three-level inverter

Proper control of the DC-bus voltage is essential for the operation of the compensator. The principle of controlling the DC-bus voltage is based on active-power control, i.e., charging the DC capacitor with active power will increase the voltage, while releasing a certain amount of active power, will decrease it. According to the pq-theory, a DC component in the dq-coordinates corresponds to the active power, and thus the DC-bus voltage control is implemented in the Synchronous reference frame [13]. The per-phase fundamental equivalent circuit of the STATCOM is shown in Fig. 2. , and the phasor diagrams are shown in Fig. 3(a) and 3(b). These diagrams can be employed in explaining the operating principles of the STATCOM.

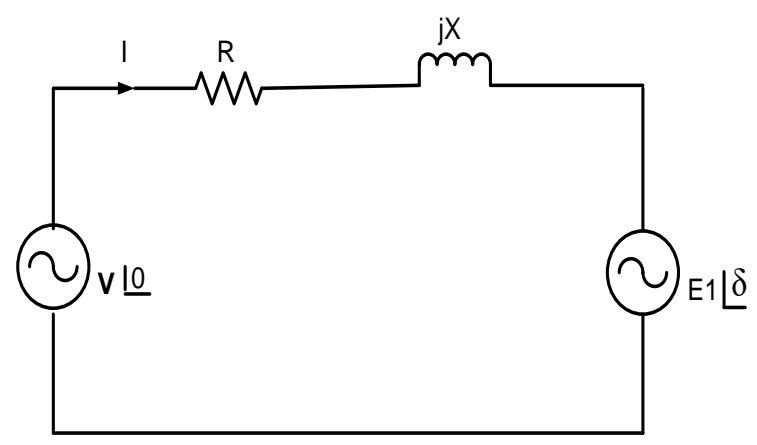

Fig. 2. Per-phase equivalent circuit of STATCOM at fundamental frequency

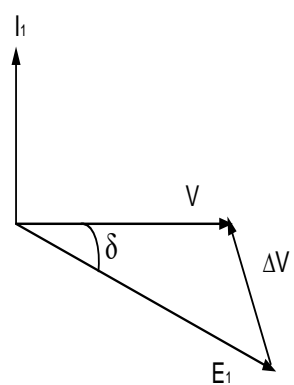

(a) Leading power factor

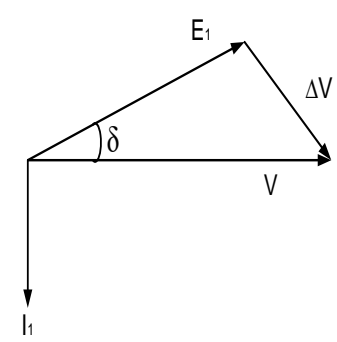

(b) Lagging power factor Fig. 3. Phasor diagrams

The STATCOM is connected to the ac mains through the linked reactor, $\mathrm{X}$. The resistor, $\mathrm{R}$ represents the total losses in the inverter. $V$ is the ac mains voltage, $I_{1}$ and $E_{l}$ are the fundamental components of current and output voltage of the inverter respectively. The line current flowing into or out of the STATCOM is always at $90^{\circ}$ to the mains voltage due to reactive coupling. Reactive power is absorbed by the STATCOM when the fundamental of the inverter output voltage is less than the ac mains voltage, whereas reactive power is generated by the STATCOM when the inverter voltage is higher. The general expression for the apparent power, $S$ flowing from the ac mains to the STATCOM can be derived from Fig. 2. Thus,

$S=V I^{*}=-\frac{V E_{1}}{X} \sin \delta+j\left\{\frac{V^{2}-V E_{1} \cos \delta}{X}\right\}$.

Switching devices of the inverter are operated to obtain the fundamental of the inverter voltage, $E_{l}$ slightly leading or lagging the system voltage, $V$ by an angle, $\delta$. In this way, net real power flows between the system and the STATCOM [14]. If the inverter output voltage, $E_{l}$ leads the system voltage, $V$ by $\delta$, real power flows from the STATCOM and the capacitor voltage decreases. But if the inverter voltage $E_{l}$ lags the system voltage $V$, real power is absorbed by the STATCOM and the capacitor voltage increases. Thus by controlling the phase angle, $\delta$ of the inverter output voltage with respect to the mains voltage, the dc capacitor voltage, $V_{d c}$ can be varied, and hence the amplitude of the fundamental component of the inverter output voltage, $E_{l}$ can be controlled [15].

\section{A. Control Circuit}

The block diagram of the control circuit of the STATCOM is shown in Fig. 4.

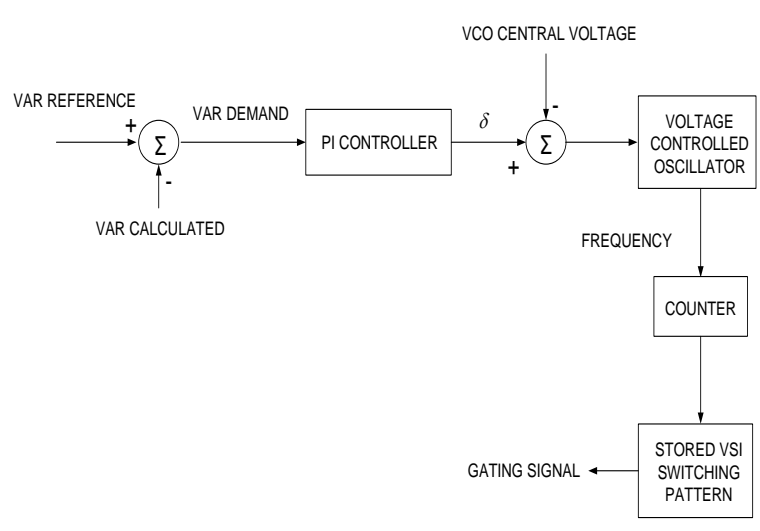

Fig. 4. The $\delta$ Phase-shift control block diagram

It consists of a proportional-plus-integral (PI) controller, an adder, a voltage controlled oscillator (VCO), a counter and a switching pattern [16], [17]. The source voltage and current are transformed into the $\mathrm{d}-\mathrm{q}$ frame for calculating the reactive power generated by the system. This is compared to the var reference. The VCO output frequency is synchronized to the ac supply frequency. Under steady-state operating conditions $(\delta=0)$, the var demand signal is zero and the stored switching pattern is read at the supply frequency, $f_{o}$. If load power factor fluctuates, the var calculated changes and the VCO will speed up or slow down to correct the error. A dc input control voltage to the VCO is adjusted to change the VCO frequency and the stored 
switching pattern is read at a different frequency. In this way the correct value for the phase shifting angle $\delta$ is provided. The reset pulse of the counter is varied to read the switching pattern. The magnitude of the var calculated signal determines the amplitude of the ac output voltage of the STATCOM, adjusting in this way the amount of reactive power generated or absorbed by the STATCOM.

\section{B. Fundamental Frequency Modulation (FFM)}

Fig. 5 shows phase and line voltage waveforms obtained in the three-level inverter by applying a switching scheme to obtain the output voltage which has intervals when the output is zero as well as $+\frac{V_{d c}}{2}$ and $-\frac{V_{d c}}{2} \quad$ [18]. The amplitude can be controlled by adjusting the interval $\alpha$ on each side of the pulse where the output is zero.

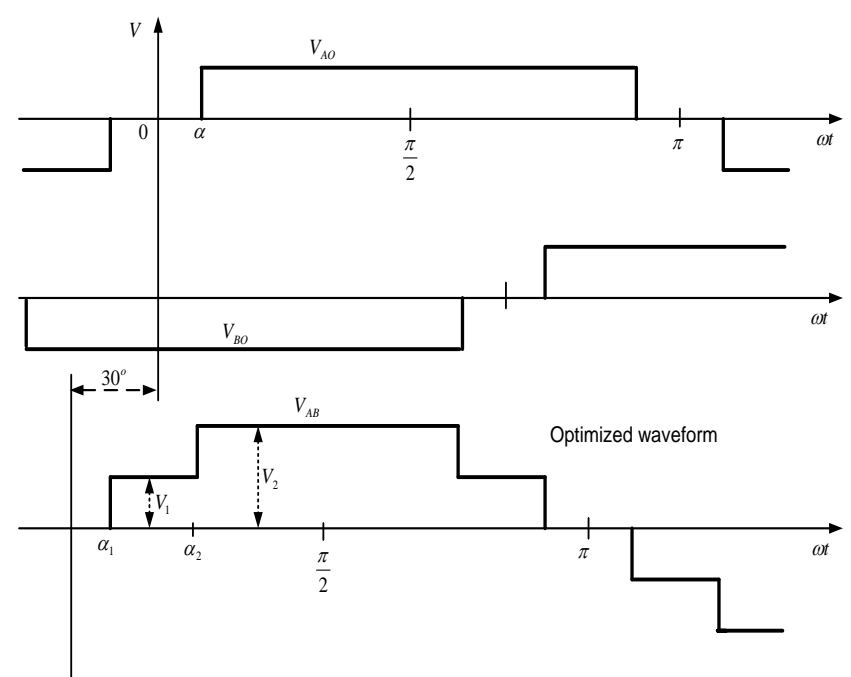

Fig. 5. Typical FFM phase and line voltages in three-level inverter

In Fig.5, the phase voltage $V_{O A}$ is given by the Fourier expression:

$V_{O A}=\sum_{n=1}^{\infty} b_{n} \sin n \omega t$

where

$b_{n}=\frac{4 V_{i}}{n \pi} \cos n \alpha$

( $\mathrm{n}$ is odd).

It can be seen that the amplitude of each frequency, and in particular the fundamental frequency of the output is a function of $\alpha$. Specific duration of a zero interval of the output can eliminate any one specific harmonic. For example, in (3), if $\alpha=18^{\circ}$, only the $5^{\text {th }}$ harmonic is eliminated, and if $\alpha=12.86^{\circ}$, only the $7^{\text {th }}$ harmonic is eliminated. This removes further controllability on the amplitude of the output and so cannot significantly reduce the total harmonic distortion (THD) or improve the waveshape. The line voltage can however be improved by optimizing the spacing of the steps. That is finding the optimum values of $\alpha_{1}$ and $\alpha_{2}$. Applying Fourier analysis to the stepped waveform and assuming odd quarter-wave symmetry,

$b_{n}=\frac{4}{\pi}\left[\int_{\alpha_{1}}^{\alpha_{2}} V_{1} \sin n \omega t d \omega t+\int_{\alpha_{2}}^{\pi / 2} V_{2} \sin n \omega t d \omega t\right]$

$$
V_{2}-V_{1}=V_{1}
$$

Since the waveform is the difference between any two phase voltages, $\alpha_{1}=\left(\pi / 3-\alpha_{2}\right)$ [19].

$b_{n}=\sum_{n=1}^{\infty} \frac{4 V_{1}}{n \pi}\left(\cos n \alpha_{1}+\cos n \alpha_{2}\right)$

$V_{o}=b_{n} \sin n \omega t$

The rms value of the fundamental component is

$V_{f}=\frac{2 \sqrt{2}}{\pi} V_{1}\left(\cos \alpha_{1}+\cos \alpha_{2}\right)$

The rms value of the stepped waveform is:

$V_{t}=\left[\frac{2}{\pi}\left\{\int_{\alpha_{1}}^{\alpha_{2}} V_{1}^{2} d \theta+\int_{\alpha_{2}}^{\pi / 2} V_{2}^{2} d \theta\right\}\right]^{1 / 2}$

The harmonic distortion can be expressed as:

$$
\begin{aligned}
& \operatorname{THD}(\%)=100\left[\frac{V_{t}^{2}}{V_{f}^{2}}-1\right]^{1 / 2} \\
& \frac{V_{t}^{2}}{V_{f}^{2}}=\frac{\pi\left(5 \pi / 12-0.5 \alpha_{2}\right)}{\left(\cos \left(\pi / 3-\alpha_{2}\right)+\cos \alpha_{2}\right)^{2}}
\end{aligned}
$$

To minimize the Total Harmonic Distortion (THD), $\frac{V_{t}^{2}}{V_{f}^{2}}$ should have a minimum value.

Let:

$\mathrm{y}=\frac{V_{t}^{2}}{V_{f}^{2}}=\frac{\pi\left(5 \pi / 12-0.5 \alpha_{2}\right)}{\left(\cos \left(\pi / 3-\alpha_{2}\right)+\cos \alpha_{2}\right)^{2}}$

To Minimize y,

$\frac{d y}{d \alpha}=0$ 
$\frac{d y}{d x}=\left(5 \pi / 3-2 \alpha_{2}\right)+\frac{\cos \left(\pi / 3-\alpha_{2}\right)+\cos \alpha_{2}}{\sin \left(\pi / 3-\alpha_{2}\right)-\sin \alpha_{2}}=0$

Solving (12) iteratively,

$\alpha_{2}=0.79 \mathrm{rad}=45.3^{\circ}$.

Thus,

$$
\alpha_{2}=45^{\circ} \text { and } \alpha_{1}=\left(\pi / 3-\alpha_{2}\right)=15^{\circ} .
$$

The phase and line voltages are shown in Fig. 6.
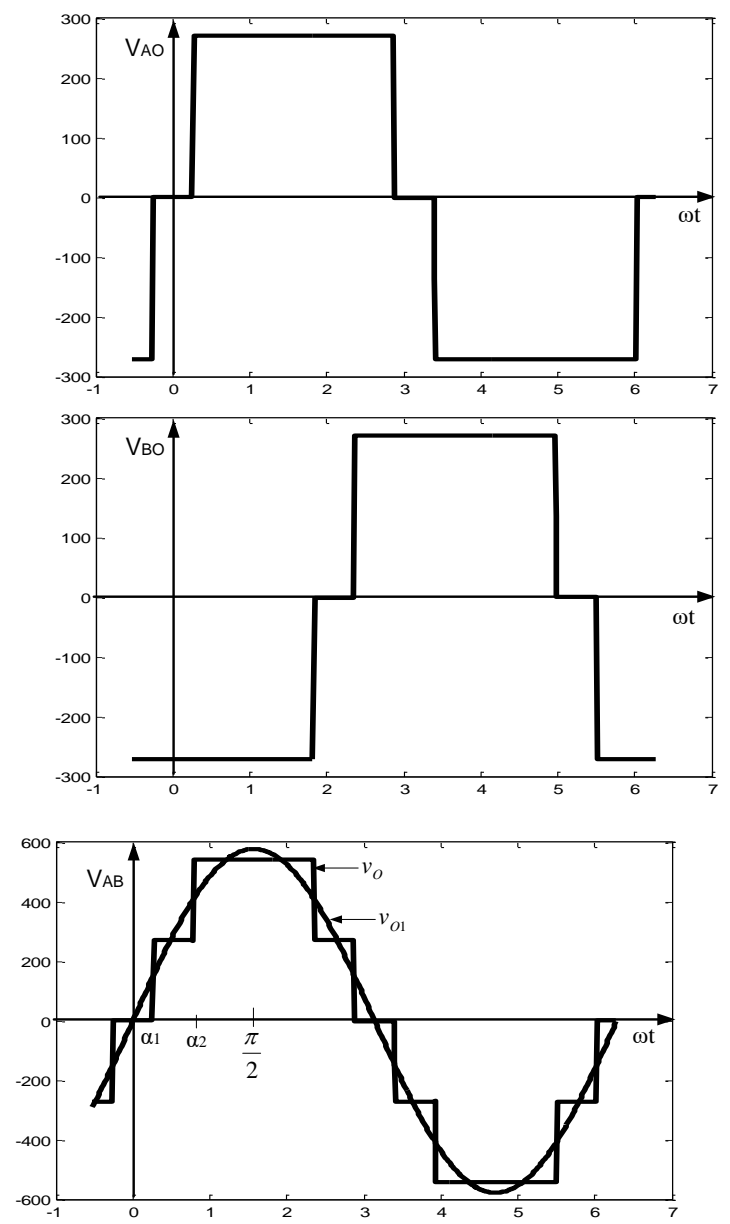

Fig. 6. Phase and Line voltages for FFM $v_{0}-$ inverter output voltage $v_{\mathrm{ol}}$ - fundamental component

This three-level output voltage has the added advantage of better waveform quality, lower total harmonic distortion (THD), and lower electromagnetic interference (EMI) over their two-level counterparts [20]. The harmonic amplitudes for the conventional waveform and the optimized waveform are shown in table I. It can be seen from the table that the THD has been reduced from 31.08 to 16.86 , and this is achieved by maintaining the same average power output in the proposed system as that of a conventional two-level PWM inverter.
TABLE I: VALUES OF PERCENTAGE HARMONIC AMPLitudes OF THE INVERTER OUTPUT VOLTAGE

\begin{tabular}{|c|c|c|}
\hline Harmonic Number & $\frac{b_{n}}{b_{1}} \%$ (conventional) & $\frac{b_{n}}{b_{1}} \%$ (optimized) \\
\hline 1 & 100 & 100 \\
\hline 5 & 20 & 0 \\
\hline 7 & 14.28 & 3.8 \\
\hline 11 & 9.09 & 9.09 \\
\hline 13 & 7.69 & 7.69 \\
\hline 17 & 5.88 & 1.58 \\
\hline 19 & 5.26 & 1.41 \\
\hline 23 & 4.35 & 4.35 \\
\hline 25 & 4.0 & 4.0 \\
\hline 29 & 3.45 & 0.92 \\
\hline 31 & 3.22 & 0.86 \\
\hline 35 & 2.86 & 0.86 \\
\hline THD $\%$ & 31.08 & 16.86 \\
\hline
\end{tabular}

\section{MODELLING OF THE STATCOM}

The STATCOM system shown in Fig. 1 is partitioned into several basic sub-circuits as shown in Fig. 7 [21]-[23]. This is to simplify analysis. The sub-circuits are (A) dc circuit, (B) switch set, (C) inductor set, (D) resistor set and (E) voltage source.

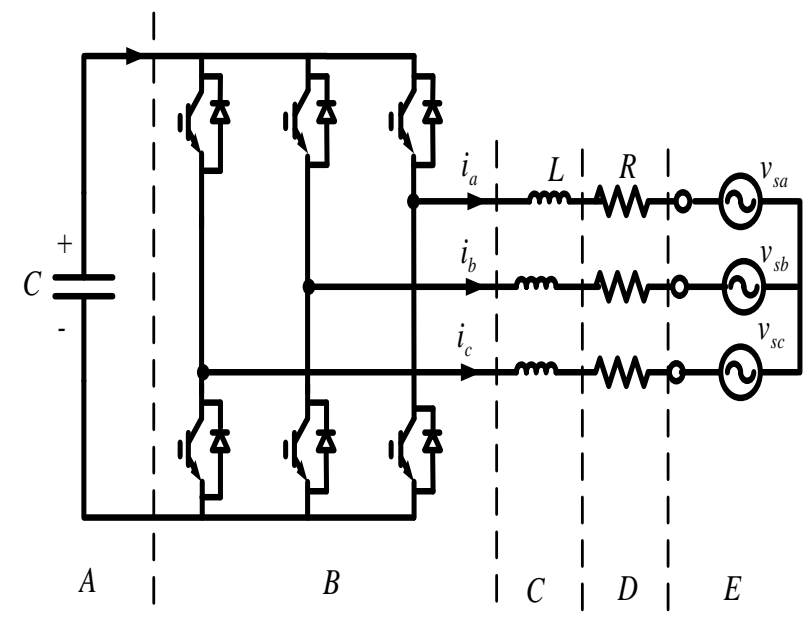

Fig. 7. Simplified main circuit of the STATCOM system.

The mathematical model is obtained by transformation into the d-q reference frame, using the Park transformation matrix of (13) [24], [25].

$K=\sqrt{2 / 3}\left[\begin{array}{ccc}\cos (\omega t) & \cos (\omega t-2 \pi / 3) & \cos (\omega t+2 \pi / 3) \\ \sin (\omega t) & \sin (\omega t-2 \pi / 3) & \sin (\omega t+2 \pi / 3) \\ 1 / 2 & 1 / 2 & 1 / 2\end{array}\right]$

The $\mathrm{d}-\mathrm{q}$ variables obtained after transformation can be shown to be:

1) For parts $A$ and $B$

$v_{o q}=0 ; v_{o d}=D v_{d c}$

$2 i_{d c}=D i_{d}$ 
The switch set is exactly equivalent to the transformer whose turn ratio is defined to be the dual value of the duty cycle of the switch set [26]

2) For parts $C$

$L \frac{d i_{q}}{d t}=-\omega L i_{d}+v_{q}-v_{o q}$

$L \frac{d i_{d}}{d t}=\omega L i_{q}+v_{d}-v_{o d}$

These equations show that it is possible to control $i_{\mathrm{d}}$ and $i_{\mathrm{q}}$, indirectly, by means of the $\mathrm{d}-\mathrm{q}$ components of the inverter voltage, $v_{\mathrm{d}}$ and $v_{\mathrm{q}}$, with a dynamic that depends on the $R$ and $L$ values of the filtering inductance [27].

3) For parts $D$ and $E$

$v_{s},{ }_{q d 0}=V_{s}\left[\begin{array}{c}-\sin \delta \\ \cos \delta \\ 0\end{array}\right]$

These equations result in the equivalent circuit of the switching system as shown in Fig. 8.

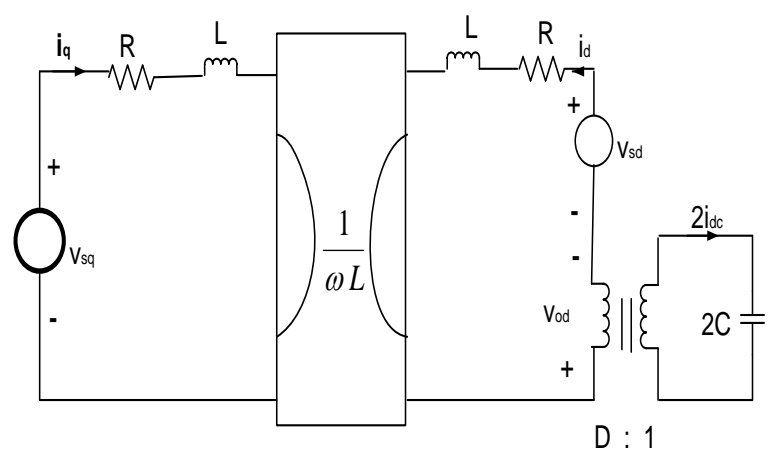

Fig. 8. Equivalent circuit of the STATCOM

For steady state operation, the inductors are shorted and the capacitor opened. When this is done, we obtain Fig. 9.

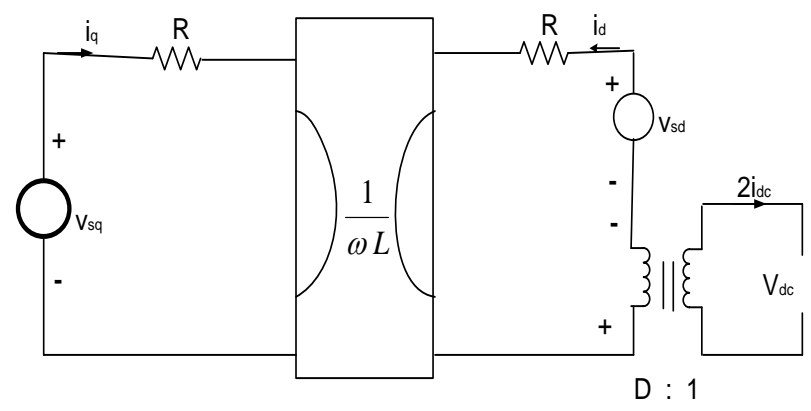

Fig. 9. DC equivalent circuits for steady state analysis.

We can obtain the following equations from Fig. 9.

$I_{q}=\frac{V_{s q}}{R}=-\frac{V_{s}}{R} \sin \delta$

$Q_{c}=V_{s q} I_{d}-V_{s d} I_{q}=-V_{s d} I_{q}$
$V_{d c}=\frac{V_{s}}{D}\left(\cos \delta-\frac{\omega L}{R} \sin \delta\right)$

Combining (6) and (21), we obtain:

$V_{o}=\sum_{n=1}^{\infty} \frac{2 V_{s}}{n \pi D}\left(\cos \delta-\frac{\omega L}{R} \sin \delta\right)\left(\cos n \alpha_{1}+\cos n \alpha_{2}\right) \sin n \omega t$

To illustrated, let us consider the transmission line having a series impedance of $(0.20+\mathrm{j} 0.538) \Omega / \mathrm{Km}$ per phase, and supplying an average load of 9.8 MW over a distance of $80 \mathrm{Km}$. The sending-end voltage is $66 \mathrm{KV}$. During peak load the receiving-end voltage drops to about $60 \mathrm{KV}$.

Equation (23) [28] shows that voltage-drop on transmission/distribution lines is dependent on the reactive power flowing on the line.

$\Delta V=\frac{X Q}{V}$

where, $\Delta V=$ voltage drop, $V=$ receiving-end voltage, $X=$ transmission line reactance, $Q=$ reactive power flowing on the line.

From (23) it can be shown that the system is operating at a power factor of 0.76 . Thus:

$Q=\frac{V . \Delta V}{X}=\frac{60000 \times 6000}{3 \times 43}=2.791 \mathrm{MVAr}$

power factor $=\cos \left[\tan ^{-1}\left(\frac{2.791}{3.27}\right)\right]=0.76$

3.27MW is the real power per phase flowing on the line.

Fig. 10 shows the waveforms of the ac voltage and current. Poor power factor in transmission and distribution networks result in poor voltage profile at the receiving end and network losses, costing millions of dollars every year [29]. Any modest reduction in transmission losses, by limiting the flow of load reactive current along the transmission lines, means considerable cost savings in both power capacity and energy production [30].

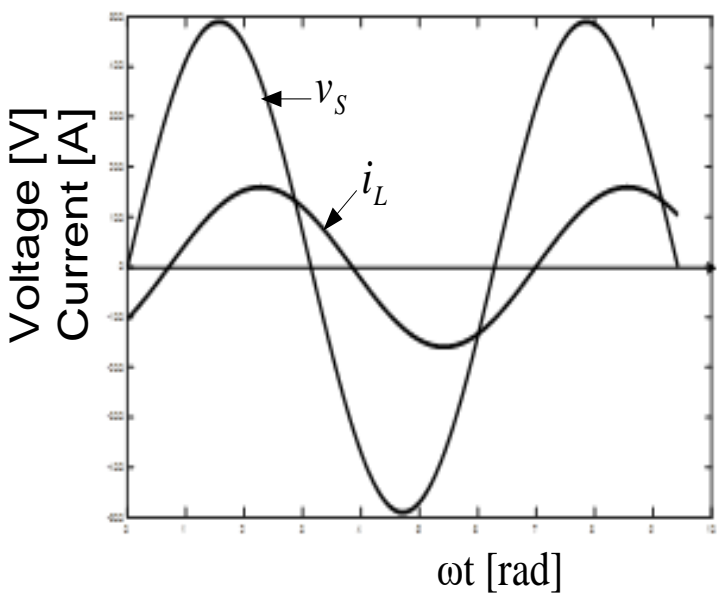

Fig. 10. AC system at power factor of 0.76 


$$
\begin{gathered}
v_{\mathrm{S}}-\text { ac system voltage } \\
i_{\mathrm{L}}-\text { load current }
\end{gathered}
$$

\section{DESIGN OF STATCOM}

The system power factor can be improved by installing the STATCOM near the load. Taking $M I=0.8$ and $R=$ $0.5 \Omega,(22)$ was solved to obtain the values of $\delta$ and $L$ which satisfy the voltage regulation and power factor $(p f)$ requirements of the ac system, i.e., $0.96<p f<1.0$. So, for unity power factor, we obtained $\delta=-2.0^{\circ}$ and $L=14.5 \mathrm{mH}$

The output voltage and current of the compensator are shown in Fig. 11.

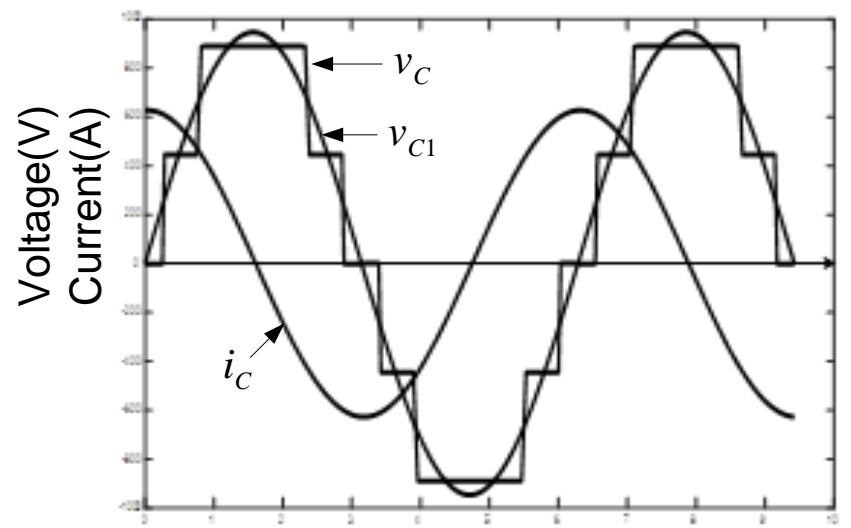

$\omega t[\mathrm{rad}]$

Fig. 11. Compensator output voltage and current $v_{\mathrm{c}}$ - output voltage $v_{\mathrm{cl}}$-fundamental component $i_{\mathrm{c}}$-output current

Fig. 12 shows the waveforms of the compensated system. It can be observed that the voltage $\left(v_{\mathrm{s}}\right)$ and the current $\left(i_{\mathrm{s}}\right)$ are in phase, i.e., unity power factor was achieved. The voltage generated by the inverter is equal to the sending-end voltage of the ac system.

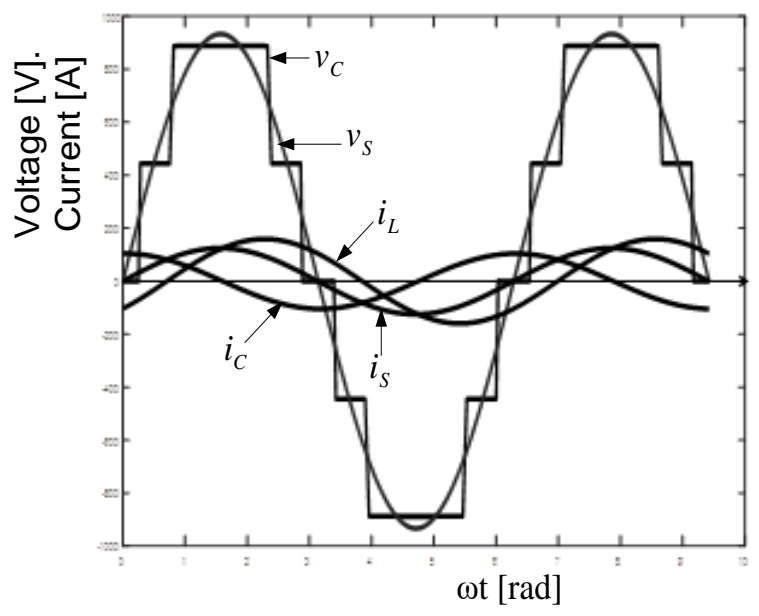

Fig. 12. Compensated system operating at unity power factor

$$
\begin{gathered}
v_{c}-\text { inverter output voltage } \\
v_{\mathrm{s}}-\text { ac system voltage } \\
i_{\mathrm{c}}-\text { compensating current } \\
i_{\mathrm{s}}-\text { source (compensated) current }=i_{\mathrm{L}}+i_{\mathrm{c}}
\end{gathered}
$$

Fig. 13 shows the compensator current, ac system voltage and currents.

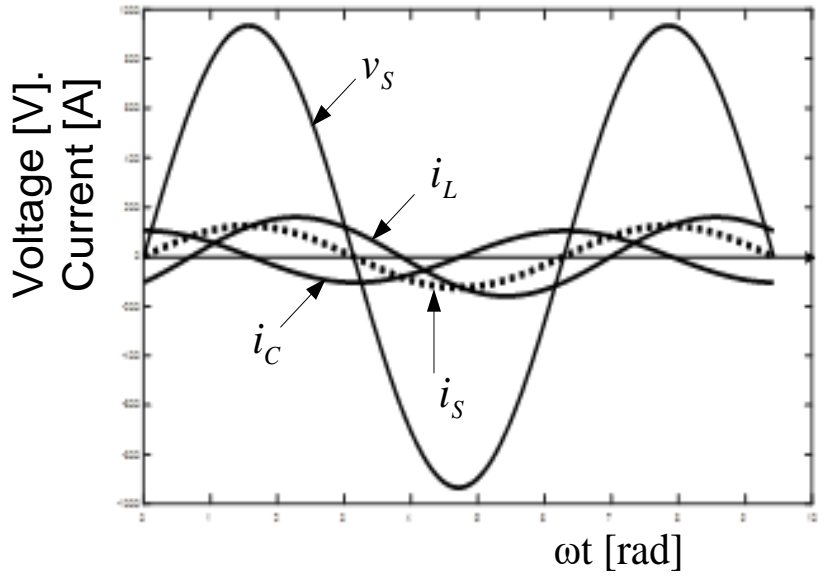

Fig. 13. System voltage and currents, showing unity power factor

Fig. 14 shows the reactive power exchange between the compensator and the ac system.

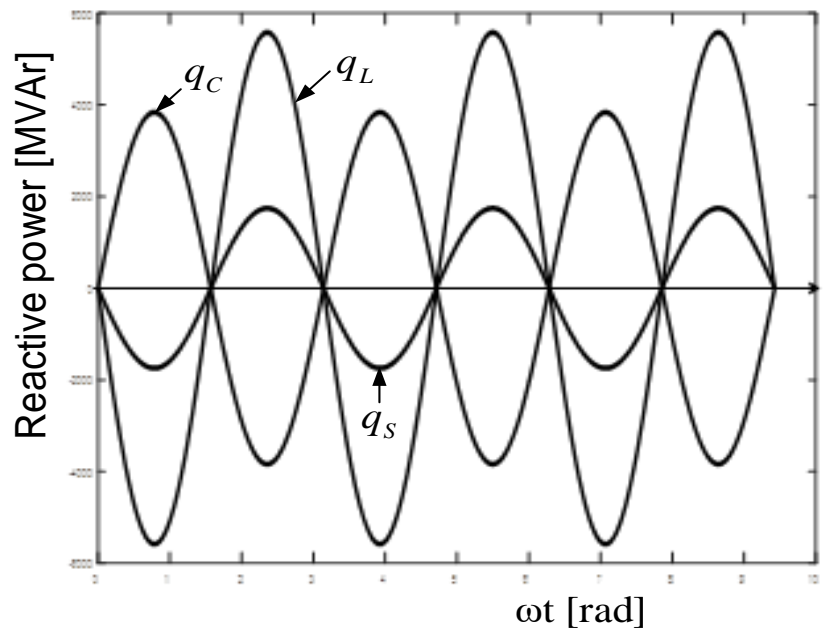

Fig. 14. Waveforms of reactive power

$q_{\mathrm{L}}$ - load reactive power flowing from the source (before compensation) $q_{\mathrm{C}}-$ reactive power generated by the compensator

$q_{\mathrm{S}}-$ Net reactive power flowing from source (after compensation)

\section{CONCLUSION}

It has been shown in this paper how the ac system operation can be optimized by the application of a STATCOM, employing FFM voltage source inverter. The power factor of the system was raised from 0.76 to unity, thereby reducing the line current from $112.75 \mathrm{~A}$ to $88.3 \mathrm{~A}$, resulting in active power loss reduction by $38.7 \%$, and consequently decreasing power costs, as well as increasing transmission system capacity. The presence of the STATCOM also reduced the reactive power flowing on the line from 2.791 MVAr per phase ( $q_{\mathrm{L}}$ in Fig. 14) to 1745 VAr per phase ( $q_{\mathrm{s}}$ in Fig. 14). Thus it can be observed that the receiving-end voltage at load bus has been raised from $60 \mathrm{kV}$ to $66 \mathrm{kV}$ due to the voltage generated by the STATCOM. The power factor $(p f)$ can be found from:

$p f=\cos \left[\tan ^{-1}\left(\frac{1745 .}{3.27 * 10^{6}}\right)\right]=1.0$

It can be observed that the reactive elements ( $L$ and $C$ ) are small in size. 


\section{REFERENCES}

[1] D. Rahul, R. S. Subhransu, K. P. Bijay, and G. V. Vijendran, "Exreme Learning Machine Based Adaptive Distance Relaying Scheme for Static Synchronous Seri Compensator Based Transmission Lines," Electric Power Components and Systems, 44(2):219-232, 2016.

[2] H. Awad, J. Svensson, and M. Bollen, "Mitigation of Unbalanced Voltage Dips Using Static Series Compensatorr," IEEE Transaction on Power Electronics, vol. 19, No. 3, pp. 837-846, May 2004.

[3] T. Davis, G.C. Beam, and C. J. Melhorn, "Voltage Sags:Their Impact on the Utility and Industrial Customers," IEEE Trans. Ind. Applicat. vol. 34, pp. 549-558, May/June 1998.

[4] M. J. Slabbert, S. J. Van Zyl, R. Naidoo, and R. C. Bansal, "Evaluating Phase Over-Current Protection Philosophies for MediumVoltage Feeders Applying Let-through Energy and Voltage Dip Minimization," Electric Power Components and Systems, 44(2):206218, 2016.

[5] N. H. Woodley, S. Middlefauff, and A. Sundaram, "Dynamic Voltage Restorer demonstration Project Experience," In Proc. 51 $51^{\text {st }}$ Annual Power Distribution Conference. Austin, TX, Oct. 19-21, 1998.

[6] H. Liu, Z. ZhiGao, "Study on SSR Characteristics of Power Systems with Static Var Compensators," AC-DC Power Transmission Conference, pp. 193-198, no. 485IEE, November 28-30, 2001.

[7] W.R.N. Santos, E. R. C. da Silva, C.B. Jacobina, E. M. Fernandes, A. C. Oliveira, R. R. Matais, D. F. Filho, O. M. Almeida, and P. M. Santos, "The Transformerless Single-phase Universal Active Power Filter for harmonic and Reactive Power Compensation," IEEE Transactions on Power Electronics, vol. 29, no.7, pp. 3563-3572, July 2014.

[8] S. A. Zemerick, P. Klinkhachorn, and A. Feliachi, "Prototype Design of a Personal Static Var Compensator," Advanced Power Engineering Research Center, West Virginia University, Morgantown, WV 26506 USA, pp. 311-315, 2002.

[9] M. Jones, I. N. Satiawan, and N. Bodo, "A Dual Five-Phase SpaceVector Modulation Algorithm Based on the Decomposition Method," IEEE Transactions on Industry Applications, vol. 48, no.6, pp. 2110 2120, November/December 2012.

[10] Wei Chen, Haiwei Sun, XinGu, and Changliang Xia, "Synchronized Space-Vector PWM for Three-Level VSI with Lower Harmonic Distortion and Switching Frequency," IEEE Transactions on Power Electronics, Vol. 31, No.9, pp. 6428-6441, September, 2016.

[11] J. B. Ekanayake, and N. Jenkins, "A Three-level Advanced Static Var Compensator," IEEE Transactions on Power Delivery, vol. 11, No. 1, pp. 540-545, January 1996.

[12] B. Singh, and K. V. Srinivas, "Three-level 12-pulse STATCOM with Constant DC Link Voltage," Annual IEEE India conference (INDICON), 18-20 Dec 2009, pp. 1-4

[13] L. Feola, R. Langella, and A.Testa, "On the behavior of three-phase inverters in the new smartgrid context," 2nd IEEE energycon conference and exhibition, Florence, 9-12 Sept 2012.

[14] D.R. Trainer, S.B. Tennakoon, and R.E. Morrison, "Analysis of GTObased static Var compensators," IEE Proc-Electric Power Appl., vol 141, pp. 293-298, November 1994.

[15] M. Benghanem, and A. Draou, "A new Modelling and Control Analysis of an Advanced Static Var Compensator using a Three-level
(NPC) Inverter Topology," Journal of Electrical Engineering, vol. 57, pp. 285-290, 2006.

[16] G. Joos, L. Moran, and P. Ziogas, "Performance Analysis of a PWM Inverter Var Compensator," IEEE Transactions on Power Electronics, vol. 6, No. 3. pp. 380 - 390. July 1991.

[17] V. K. Sood, HVDC and FACTs Controllers - Applications of Static Converters in Power Systems, Springer, New York, USA, 2004, ch. 3, pp. 41-42.

[18] D. W. Hart, Introduction to Power Electronics, Prentice Hall, Upper Saddle River, New Jersey 07458, 1997, pp. 302-303.

[19] M. P. Bhagwat, and V. R. Stefanovic, "Generalized Structure of a Multilevel PWM Inverter," IEEE Transactions on Industry Applications, vol.1A-19, No.6, pp. 1057-1068, November/December 1983.

[20] R. Naderi, A. K. Sadigh, and K. M. Smedley, "Dual Flying Capacitor Active.Neutral-Point-Clamped Multilevel Converter," IEEE Transactions on Power Electronics, vol. 31, No.9, pp. 6476-6484, September, 2016.

[21] C. Han, A. Q. Huang, M.E. Baran, S. Bhattacharya, W. Litzenberger, L. Anderson, and J. A. Edris, "A STATCOM impact study on the integration of a large wind farm into a weakloop power system," IEEE Trans on Energy Conversion, 23(1):226-233, 2008.

[22] B. Singh, R. Saha, A. Chandra, and A. Haddad, "Static synchronous compensators(STATCOM) a review," IET Power Electronics 2(4):297-324, 2009.

[23] D. Ramirez, S. Martinez, F. Blazquez, and C. Carrero. "Use of STATCOM in wind farms with fixed-speed generators for grid code compliance," Renew Energy 37(1):202-212, 2012.

[24] F. Shahnia, S. Rajakaruma, and A. Gosh, Static Compensator (STATCOMs) in Power Systems, Springer Singapore, 2015, pp. 175.

[25] G. C. Cho, C. T. Rim, N. S. Choi, and G. H. Cho, "Modeling, Analysis and Control of Static Var Compensator Using Three-level Inverter," IEEE Transactions on Power Delivery, vol. 11, no. 1, pp. 837-843, October 2008.

[26] C. T. Rim, D. Y. Hu, and G. H. Cho, "Transformers as Equivalent Circuits for Switches: General Proofs and D - Q TransformationBased Analyses," IEEE Transactions on Industry Applications, vol. 26, pp. 777-784, July/August 1990

[27] R. A. Kantaria, S. K. Joshi, and K. R. Siddhapura, "Novel hysteresis control technique of VSI based STATCOM," In: Proceedings of the India international conference on power electronics (IICPE). IEEE, New Delhi, 2011.

[28] B.M Weedy, Electric Power Systems, second edition, London: John Wiley \& Sons, 1975, pp. 43-44.

[29] A. E. Ferganni, "Multi-objective Allocation of Multi-Type Distributed Generators along Distribution Networks Using Backtracting Search Algorithm and Fuzzy Expert Rules," Electric Power Components and Systems, 44(3):252-267, 2016.

[30] A.E. Hammad, "Comparing the Voltage Control Capabilities of Present and Future Var Compensating Techniques in Transmission Systems," IEEE Transactions on Power Delivery, vol. 11, No.1, pp. 475-484, January, 1996. 